\title{
PENATAAN RUANG PUBLIK TEPI SUNGAI UNTUK MENGHIDUPKAN KEMBALI FUNGSI SUNGAI KOTA JAKARTA
}

\author{
Jessica Wijaya ${ }^{1)}$, Suryono Herlambang ${ }^{2)}$ \\ 1)Program Studi S1 Arsitektur, Fakultas Teknik, Universitas Tarumanagara, jes16hxf@gmail.com \\ 2) Program Studi S1 PWK, Fakultas Teknik, Universitas Tarumanagara, suryonoh@ft.untar.ac.id
}

\begin{abstract}
Abstrak
Sejak pertama manusia mulai menjalani gaya hidup menetap, sungai memiliki peran yang signifikan dalam kehidupan masyarakat dan dalam perkembangan permukiman. Peran sungai untuk kehidupan masyarakat kota juga telah berubah beberapa kali. Mulai dari fungsi sebagai pertahanan, jalur perdagangan, perikanan, logistik, hingga rekreasi. Namun dengan semakin modernnya kota Jakarta muncul pandangan bersifat destruktif terhadap sungai dan menghilangkan apresiasi masyarakat kota terhadap sungai. Sungai kota juga telah lama ditinggalkan dan diletakan dibelakang bangunan. Masyarakat kota tidak dapat menikmati sungainya karena tidak adanya akses yang menghubungkan perairan sungai dengan daratan bagi masyarakat. Lokasi proyek terletak di Kelurahan Pejagalan di antara Kali Angke dan Kanal Banjir Barat. Proyek didesain sebagai pusat kebudayaan dengan fasilitas yang mewadahi kegiatan masyarakat di tepian sungai. Proyek akan menjadi ruang publik bagi masyarakat untuk berinteraksi, berekreasi, dan melakukan kegiatan olahraga, komersial, dan seni. Metode penulisan yang digunakan adalah pendekatan kualitatif melalui penjabaran dengan metode deskriptif dengan teknik pengumpulan data melalui survey lapangan dan pencarian data terkait objek studi berupa data dari instansi pemerintah, studi literatur, buku, jurnal, dan informasi dari internet. Metode perancangan yang digunakan adalah metode pendekatan keseharian yang dijadikan sebagai program pada proyek.

Kata kunci: Ekologi; Pusat Kebudayaan; Sungai Kota; Tepi air
\end{abstract}

\begin{abstract}
Since humans first started living a sedentary lifestyle, river has played a significant role in people's lives and in the development of settlements. The role of river in urban life has also changed several times. Starting from the function as defense, trade routes, fisheries, logistics, to recreation. However, with the modernization of the city of Jakarta, a destructive view of river has emerged and has diminished the appreciation of the citizen for river. The city river has also long been abandoned and is located behind the building. The citizen cannot enjoy the river because there is no access that connects the river water with the mainland for the community. The project site is located in Kelurahan Pejagalan between Kali Angke and Kanal Banjir Barat. The project is designed as a cultural center with facilities for community activities on the riverfront. The project will be a public space for the community to interact, have recreation, and engage in sports, commercial and artistic activities. The writing method used is a qualitative approach through elaboration with descriptive methods with data collection techniques through field surveys and data search related to the object of study in the form of data from government agencies, literature studies, books, journals, and information from the internet. The design method used is an everydayness method.

Keywords: City River; Cultural Center; Ecology; Waterfront
\end{abstract}

\section{PENDAHULUAN}

\section{Latar Belakang}

Sejak pertama manusia mulai menjalani gaya hidup menetap, sungai memiliki peran yang signifikan dalam kehidupan masyarakat dan dalam perkembangan permukiman. Perdagangan, transportasi, pertahanan, industri dan kebudayaan berkembang pesat di daerah dekat sungai yang dapat dilayari sebagai jalur transportasi. Salah satu kota yang juga dilalui oleh sungai adalah 
Jakarta. Seiring dengan perkembangan peradaban, hubungan antara manusia dan sungai, pemanfaatan fungsi sungai, serta peran sungai untuk kehidupan masyarakat kota, juga telah berubah beberapa kali. Mulai dari fungsi sebagai pertahanan, jalur perdagangan, perikanan, logistik, hingga rekreasi. Perkembangan kota Jakarta yang semakin modern membuat sungai kota kini hanya dilihat sebagai saluran drainase semata dan tidak dipandang sebagai ekosistem. Pandangan seperti ini dapat memberikan implikasi yang bersifat destruktif terhadap sungai dan menghilangkan apresiasi masyarakat kota terhadap sungai. Menurut data tingkat pencemaran air sungai dari Dinas Lingkungan Hidup Jakarta (2017) sebanyak 61\% sungai di Jakarta tercemar berat, $27 \%$ tercemar sedang dan $12 \%$ tercemar ringan. Pencemaran sungai paling banyak diakibatkan oleh limbah rumah tangga $(72,2 \%)$, disusul limbah perkantoran $(17,3 \%)$ dan limbah industri $(9,9 \%)$. Sungai kota juga telah lama ditinggalkan dan diletakan dibelakang bangunan sehingga sungai kerap kali diperlakukan seperti tempat pembuangan sampah. Hal ini ditambah dengan adanya struktur dinding tinggi pada sungai sehingga sungai tidak bisa diakses oleh masyarakat.

\section{Rumusan Permasalahan}

Berdasarkan latar belakang tersebut, yang menjadi permasalahan adalah tidak adanya akses yang menghubungkan perairan sungai dengan daratan bagi masyarakat. Hal yang perlu digali adalah mengenai bentuk ruang arsitektur yang dapat bernegosiasi merespon dinamika air sungai sehingga masyarakat kota dapat kembali melihat sungai sebagai bagian dari ekosistem kota. Batasan objek studi adalah sungai di Jakarta dengan area perencanaan di Kelurahan Pejagalan yang dibatasi oleh Kali Angke dan Kanal Banjir Barat.

\section{Tujuan}

Proyek ini bertujuan untuk mengekspolarasi bentuk dan program yang menunjang aktivitas di tepi sungai. Proyek akan menjadi ruang publik dimana manusia, sungai, dan alam dapat saling berinteraksi sehingga dapat mendekatkan dan meningkatkan kesadaran masyarakat terhadap sungai dan mengembalikan fungsi sungai.

\section{KAJIAN LITERATUR}

\section{Ekologi}

Istilah "ekologi" diciptakan oleh ahli zoologi Jerman, Ernst Haeckel pada tahun 1866. Kata ekologi berasal dari Bahasa Yunani yaitu 'oikos' yang berarti rumah dan 'logos' yang berarti ilmu. Sehingga ekologi berarti ilmu yang mempelajari tentang rumah/lingkungan tempat tinggal suatu makhluk hidup. Ekologi berbicara mengenai hubungan atau interaksi makhluk hidup terhadap kondisi lingkungannya. Hubungan tersebut berupa suatu jaringan (network) yang kompleks. Agustinus Sutanto (2021) menyimpulkan terdapat 6 parameter dalam arsiktektur menuju melampaui (beyond) ekologi yang dapat digunakan yaitu:

\section{Energy and Emission}

Kemampuan untuk menerapkan zero $\mathrm{CO}_{2}$ emission dalam pengoperasionalan bangunan dan meminimalisis efek karbon dalam material dan konstruksi.

\section{Adaptation}

Kemampuan untuk melakukan riset dan desain yang berkaitan dengan berbagai dampak, seperti naiknya suhu bumi, naiknya permukaan laut, kekeringan, banjir, kelangkaan pangan, perubahan populasi dan lain sebagainya.

\section{Resilience}

Kemampuan untuk membangun kelanjutan 'hunian' dan pemulihan cepat setelah kejadian guncangan, bencana alam, gangguan listrik atau iklim. 


\section{Sustainable Digital}

Kemampuan untuk melihat data-data lingkungan sebagai big data dalam menentukan taktik dan strategi dalam membangun kualitas spasial.

\section{New Technology}

Kemampuan memanfaatkan teknologi terbaru untuk meningkatkan kualitas terapan ruang konstruksi dan program bangunan

\section{Context}

Kemampuan dalam melihat posisi 'tempat' dalam hubungan dengan lingkungan (florafauna, biotik-abiotik) dimana sebuah konfigurasi keruangan akan ditempatkan.

\section{Sungai}

Sungai adalah air tawar yang mengalir dari sumbernya di daratan menuju dan bermuara di laut, danau, atau sungai lain yang lebih besar (Dinamika Hidrosfer, 2018). Struktur sungai terdiri dari bantaran sungai, sempadan sungai, dan palung sungai yang dapat dilihat pada gambar 1.

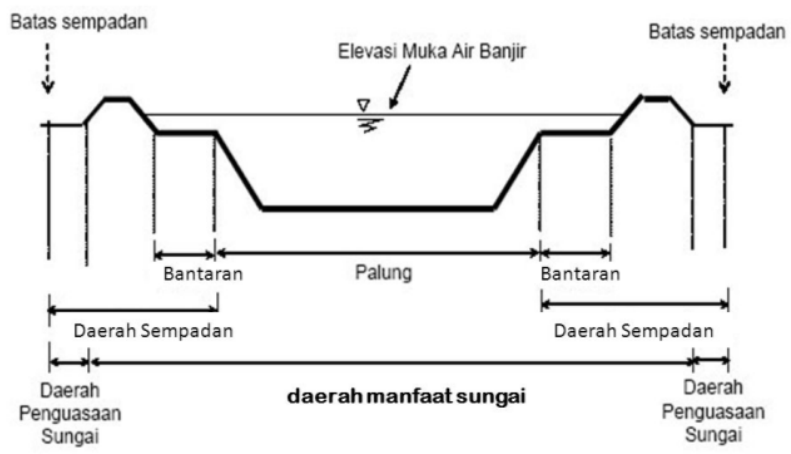

Gambar 1. Struktur Sungai

Sumber: Dinas PUP\&ESDM DIY, 2013

Berdasarkan Perarturan Pemerintah Republik Indonesia no. 38 tahun 2011, bantaran sungai adalah ruang antara tepi palung sungai dan kaki tangguul sebelah dalam yang terletak di kiri dan/atau kanan palung sungai. Sempadan adalah garis maya di kiri dan kana paling sungai yang ditetapkan sebagai batas perlindungan sungai. Palung sungai berfungsi sebagai ruang wadah air mengalir dan sebagai tempat berlangsungnya ekosistem sungai.

\section{Waterfront}

Waterfront diartikan sebagai "the dynamic area of the cities and towns where land and water meet" (Breen dan Rigby, 1994). Keberadaan air di kawasan tepian air juga memberikan manfaat ekologis, ekonomi, dan sosial bagi sebuah kota (Dewi $P$, 2017). Terdapat tiga aspek penting yang mempengaruhi terbentuknya suatu kawasan waterfront yaitu adanya ruang, waktu dan penghuni (Timur,2013). Ruang diartikan sebagai struktur spasial, waktu diartikan sebagai struktur alami dan penghuni diartikan sebagai struktur sosial. Ketiga hal inilah yang membentuk suatu budaya (Yang, 2006). Kawasan tepian air menjadi tempat dimana nilai-nilai lingkungan, sosial, ekonomi dan budaya dapat tumbuh dan berkembang. Menurut Zhang (2002) terdapat tujuh elemen yang harus dikembangkan dalam perencanaan waterfront, yakni:

1. Elemen tanah dan air

2. Desain perkotaan dan estetika

3. Rekreasi

4. Akses publik

5. Sirkulasi dan parkir

6. Sejarah dan budaya

7. Kualitas lingkungan 


\section{Sungai di Jakarta}

Jakarta dilalui oleh 13 sungai yang bermuara ke Teluk Jakarta. Sungai Ciliwung merupakan salah satu sungai penting di Jakarta. Dahulu, Sungai Ciliwung menjadi salah satu sumber kehidupan masyarakat Jakarta dan menjadi habitat berbagai jenis ikan. Sungai tersebut memiliki peran utama sebagai penampung air hujan, mengalirkan air ke hilir dan mencegah banjir. Tidak jarang sungai juga dimanfaatkan untuk memenuhi kebutuhan sehari-hari, baik untuk keperluan mandi, mencuci, memasak, menyiram tanaman dan berbagai keperluan lainnya. Sungai di Jakarta juga dimanfaatkan sebagai area rekreasi, dari sekadar melihat-lihat hingga berenang didalamnya. Ciliwung juga berfungsi sebagai jalur transportasi sungai untuk angkutan orang dan barang.

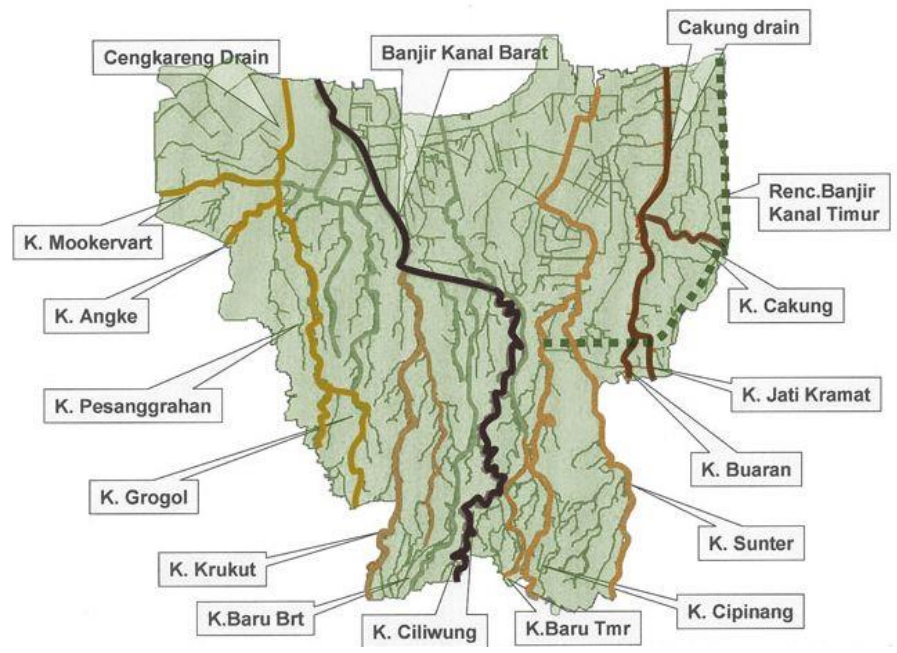

Gambar 2. Sungai-sungai di Jakarta

Sumber: Wikipedia, 2012

Namun saat ini, kondisi sungai-sungai di Jakarta sudah tercemar. Pencemaran sungai ini sebagai akibat dari masih minimnya fasilitas pengolaha pembuangan kota, terutama masyarakat bantaran sungai, sehingga mau tidak mau langsung membuang limbah ke sungai. Ditambah lagi dengan kebiasaan masyarakat yang membuang sampah sembarangan ke sungai. Tata ruang pemukiman menempatkan sungai di belakang rumah. Posisi belakang tersebut seolah membuat masyarakat memandang sungai sebagai tempat pembuangan sampah yang disembunyikan di belakang dan tidak terlihat dari depan. Akibat perbuatan tersebut sungai menjadi semakin kotor, bau, dan hitam. Sungai yang tercemar memberikan berbagai dampak buruk seperti bencana banjir, munculnya berbagai penyakit, berkurangnya ketersediaan air bersih, dan menghilangnya ekosistem air yang ada di sungai.

\section{Banjir di Jakarta}

Membicarakan sungai tidak dapat lepas dari dinamika airnya. Kita dapat melihat perubahan kenaikan dan penurunan air sungai ketika musim hujan dan musim kemarau. Selain perubahan level air, sungai juga mengalami perubahan bentuk. Namun di sebagian besar kota-kota saat ini, sungai-sungai sebagian besar telah diluruskan dan diubah bentuk aslinya. Cara sungai membentuk lanskap hampir tidak terlihat lagi (Prominski, Martin dkk. 2012). Banjir juga merupakan salah satu fenomena dinamika air sungai. Selain karena sungai yang tercemar dan banyak sampah, banjir di Jakarta juga diakibatkan oleh penurunan permukaan tanah, daerah resapan air berkurang, penyempitan sungai, curah hujan tinggi, banjir kiriman dari kota di sekitaran dan lain sebagainya. Banjir yang tiap tahun selalu terjadi menjadi suatu fenomena yang tidak dapat dipisahkan dari kota Jakarta terutama di musim hujan. Salah satu upaya pemerintah dalam mengatasi banjir di Jakarta adalah dengan membangun kanal banjir Jakarta. Terdapat dua kanal banjir yaitu Kanal Banjir Barat (KBB) dan Kanal Banjir Timur (KBT). Kanal banjir ini berfungsi 
sebagai saluran kolektor genangan air dan mengalirkannya ke laut. Namun, keberadaan kanal banjir ternyata belum menyelesaikan masalah banjir di Jakarta.

\section{METODE}

\section{Metode Penelitian}

Penulis menggunakan pendekatan kualitatif melalui penjabaran dengan metode deskriptif. Teknik pengumpulan data yang dilakukan adalah sebagai berikut:

a. Data Primer

Pengumpulan data primer diperoleh dengan survey lapangan. Survey lapangan dilakukan untuk mengetahui kondisi eksisting objek yang akan diteliti. Survey lapangan dilakukan secara daring melalui google earth dikarenakan kondisi pandemi yang belum memungkinkan untuk datang secara langsung.

b. Data Sekunder

Pengumpulan data sekunder dilakukan dengan pencarian data terkait objek studi berupa data dari instansi pemerintah, studi literatur, buku, jurnal, dan informasi dari internet.

\section{Metode Perancangan}

Metode yang digunakan adalah metode pendekatan keseharian. Keseharian adalah sebuah kondisi nyata yang secara berulang terjadi dalam kehidupan, yang dilahirkan oleh kebutuhan sehari-hari sebagai bagian dari manusia dalam mengisi ruang kehidupannya (Sutanto, 2020). Pada buku Metode Desain oleh Agustinus Sutanto (2020) dijelaskan terdapat 3 taktik dan strategi pendekatan arsitektur keseharian, yaitu:

1. Drawing the everyday

Yaitu membaca tentang bagaimana masyarakat menghasilkan ruang sosial melalui kesehariannya. Strategi penerapan desain dengan memasukan kegiatan masyarakat sekitar untuk dijadikan program.

\section{Dialogue}

Yaitu membuat ruang arsitektur menjadi terbuka berarti mengajak pengguna untuk berpartisipasi di dalamnya. Strategi penerapan dengan melakukan pembagian zona berdasarkan interaksi manusia- manusia, manusia- tanaman, dan manusia-air sungai.

\section{Story telling}

Yaitu menetapkan sudut pandang dalam melihat keseharian. Sudut pandang diambil adalah spekulasi dengan adanya program di tapak, masyarakat menjadi lebih dekat dengan sungai. Masyarakat bisa lebih melihat keadaan sungainya, lalu mulai merawatnya sehingga sungai semakin bersih dan beberapa fungsi sungai kembali (ruang publik, ruang sosial, transportasi, habitat fauna \& flora).

\section{DISKUSI DAN HASIL}

\section{Analisis Lokasi}

Dalam pemilihan lokasi terdapat beberapa pertimbangan yaitu:

a. Merupakan daerah yang dilalui dan bebatasan langsung dengan sungai/kanal sebagai salah satu ciri waterfront.

b. Memiliki aksesibilitas yang mudah dengan lebar jalan utama dapat dilewati minimal 2 mobil $( \pm 6 \mathrm{~m})$ untuk memudahkan perpindahan pengunjung.

c. Dekat dengan area pemukiman: penghuni di kawasan akan menjadi pengguna utama. Berdasarkan kriteria tersebut maka lokasi tapak terpilih berada di Jl. Teluk Selatan, Kelurahan Pejagalan, Kecamatan Penjaringan, Jakarta Utara. Dari posisi tapak terdapat berbagai alam perkotaan lain seperti Suaka Margasatwa Muara Angke, Mangrove Ecotourism Center PIK, Waduk Pluit, Waduk Teluk Gong, Taman Hutan Kota Penjaringan dan RPTRA Kalijodo. 


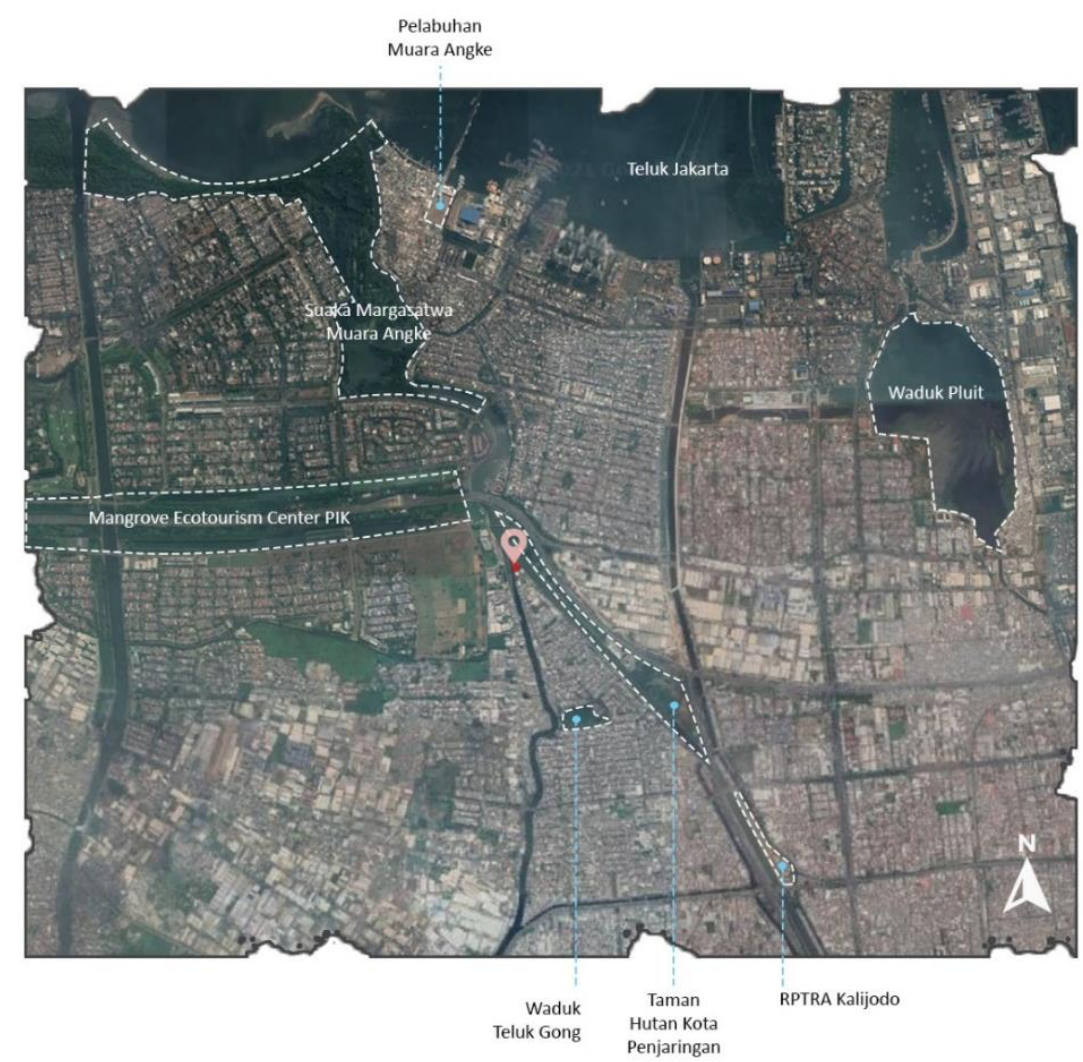

Gambar 3. Kegiatan Masyarakat

Sumber: Google Street View, 2021

Tapak terletak di segitiga pertemuan antara Kali Angke dan Kanal Banjir Barat. Aliran air sungai kemudian melewati Muara Angke dan berakhir di Teluk Jakarta. Lebar Kali Angke dan Kanal Banjir Barat masing-masing 60 meter dan lebar pertemuan keduanya adalah 112 meter. Kondisi Kanal Banjir Barat dan Kali Angke berwarna keruh dan ada sampah pada permukaan air. Pada aliran Kali Angke tercemar oleh limbah industri dan limbah domestik. Ketinggian air banjir bervariatif antara $30-160 \mathrm{~cm}$ bahkan pernah lebih dari 2 meter.
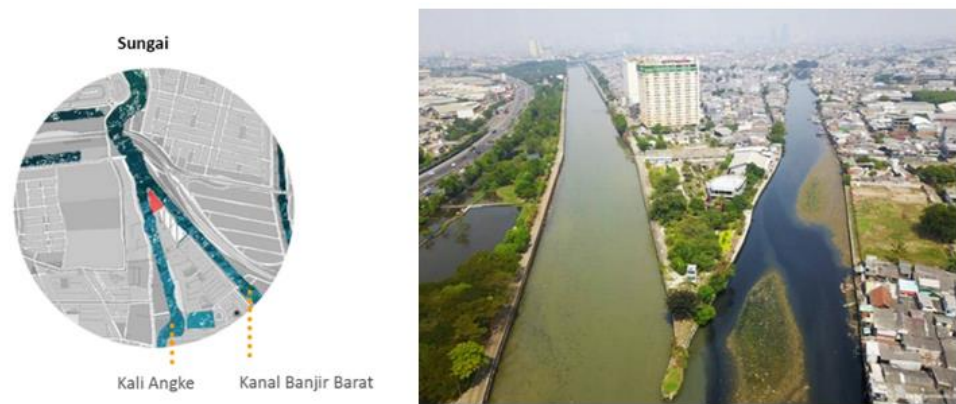

Gambar 4. Kondisi Kali Angke dan Kanal Banjir Barat

Sumber: jakartasatu, 2021 (kiri) \& dokumentasi Sintang. B, 2020 (kanan)

Tapak terletak di ujung dan hanya dapat diakses melalui Jl. Teluk Selatan. Sekitar tapak dikelilingi jalan inspeksi selebar 7 meter. Tapak tidak banyak dilalui kendaraan bermotor karena posisi tapak yang berada di ujung. Posisi tapak dapat menciptakan konektivitas aktivitas dengan hutan kota dan pemukiman, hingga Suaka Margasatwa Muara Angke melihat dari jalur sungai yang mengarah kesana. 
View ke arah tapak terlihat jelas dari 3 sisi yaitu Taman hutan kota, jalan jembatan, dan area pemukiman. View dari tapak juga berada pada 3 sisi yang menghadap sungai. Proyek dapat membuat bukaan-bukaan dengan perspective of view yang memanfaatkan pemandangan untuk menciptakan point of interest dengan mengaitkan indera visual ke alam lingkungan sekitar.

\section{Analisis Program Kegiatan}

Kegiatan masyarakat kelurahan Pejagalan sebagian besar berupa kegiatan komersial (kuliner \& toko-toko), sosial (nongkrong, bermain, dan bercakap-cakap), dan olahraga (menjala ikan, memancing ikan, penyebrangan perahu eretan, dan berenang). Posisi tapak juga diapit oleh Hutan Taman Kota Penjaringan di sisi timur dan pemukiman penduduk di sisi barat. Kegiatan di hutan kota berupa kegiatan olahraga seperti jogging, piknik, memancing ikan, dan bersepeda. Kegiatan di pemukiman berupa kegiatan komersial (warung) dan sosial (bermain dan bercakapcakap). Aliran sungai juga melewati area Suaka Margasatwa Muara Angke (SMMA) dan Mangrove Ecotourism Center PIK. Dari aliran air sungai dapat menciptakan hubungan aktivitas dengan tapak. Kegiatan di SMMA dan Mangrove Ecotourism Center PIK sebagian besar berupa kegiatan konservasi mangrove untuk menjaga habitat hewan-hewan. Ada juga kegiatan olahraga dan komersial seperti mendayung perahu kecil / kano, penginapan, birdwatching, menelusuri jalan setapak, dan fotografi.

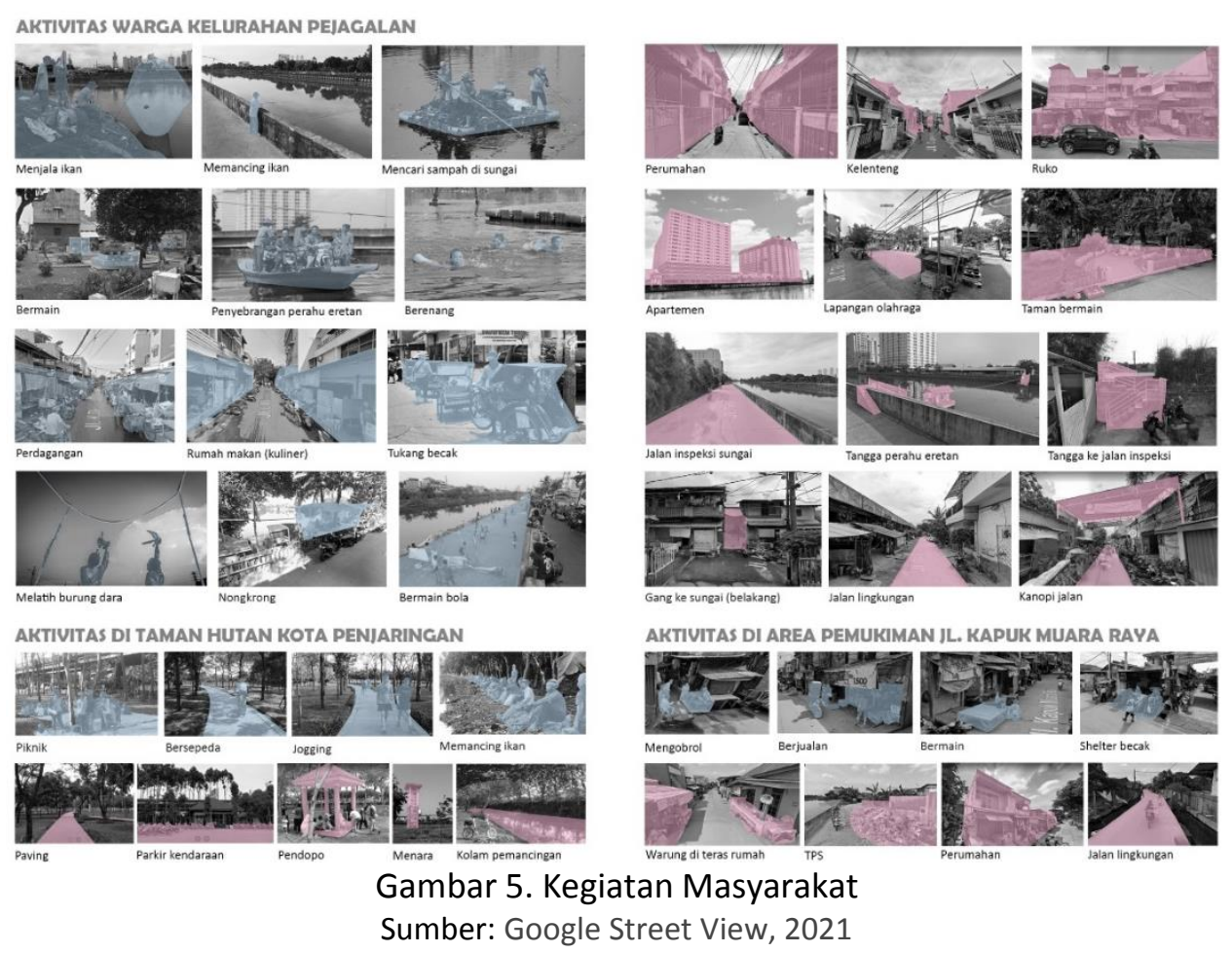

Program pada proyek menyesuaikan dengan kegiatan masyarakat sekitar. Program dibagi menjadi 3 zona yaitu:

1. Zona Red berisi kegiatan yang berhubungan dengan interaksi manusia dengan manusia. Adapun program kegiatannya yaitu amphiteater, food court, retail, café, galeri, dan playscape.

2. Zona $\mathrm{G}$ berisi kegiatan yang berhubungan dengan interaksi manusia dengan alam hijau. Program kegiatan di zona ini meliputi community garden, piknik, sculpture park, dan jogging track.

3. Zona B berisi kegiatan yang berhubungan dengan interaksi manusia dengan sungai. Pada zona ini terdapat instalasi pada sungai berupa dek kolam renang, dek memancing, dan dek kano. 


\section{Proses Desain}

Proses gubah massa dimulai dari pembagian zoning tapak menjadi 3 kemudian menentukan entrance masuk tapak yang dapat diakses dari berbagai arah (dari arah pemukiman, taman, dan sungai). Area parkir terletak dekat jalan utama, yaitu Jl. Teluk Selatan. Akses ke tapak diprioritaskan bagi pejalan kaki dan pesepeda. Lalu, posisi tapak dinaikan $60 \mathrm{~cm}$ dari jalan dan bentuk massa memaksimalkan bentuk tapak. Massa dibagi 2 memanjang arah timur barat untuk menciptakan konektivitas visual antara pemukiman, tapak dan hutan kota. Lantai dasar berupa pilotis sebagai respon terhadap banjir yang sering terjadi dan antisipasi banjir pada masa depan yang kemungkinan bertambah. Ketinggian bangunan menyesuaikan skyline dimana ketinggian semakin menurun ke arah sungai. Lalu memberi bukaan-bukaan pada massa ke lingkungan sekitar. Pada area hijau dibagi menjadi beberapa bagian dengan menciptakan jalur pejalan kaki berbentuk zig zag. Pada sisi-sisinya diciptakan pocket-pocket area duduk yang menghadap sungai. Instalasi pada sungai meneruskan garis zig zag pada taman untuk menciptakan kesatuan dengan tapak.

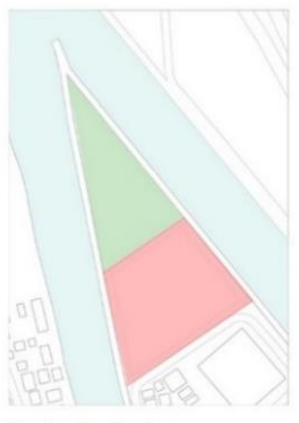

Pembagian Zoning

Tapak terdiri dari 3 zona yait zona $\mathrm{R}$ (area bangunan), zona $\mathrm{G}$ (area taman), dan zona B (area sungai)
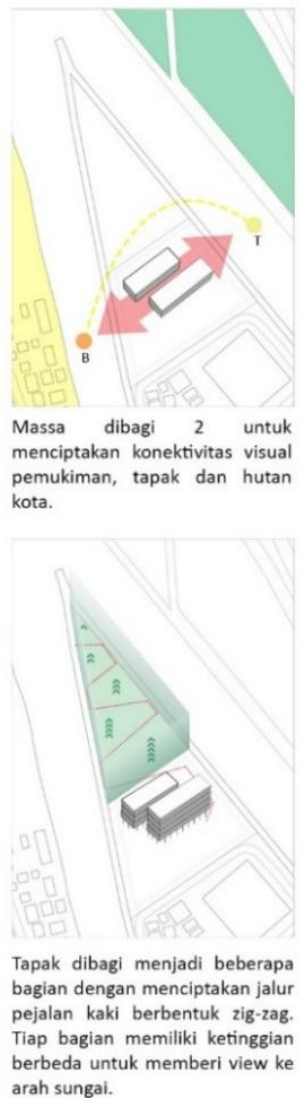

Gambar 6. Diagram Proses Gubah Massa

Sumber: Penulis, 2021 arah sungai.

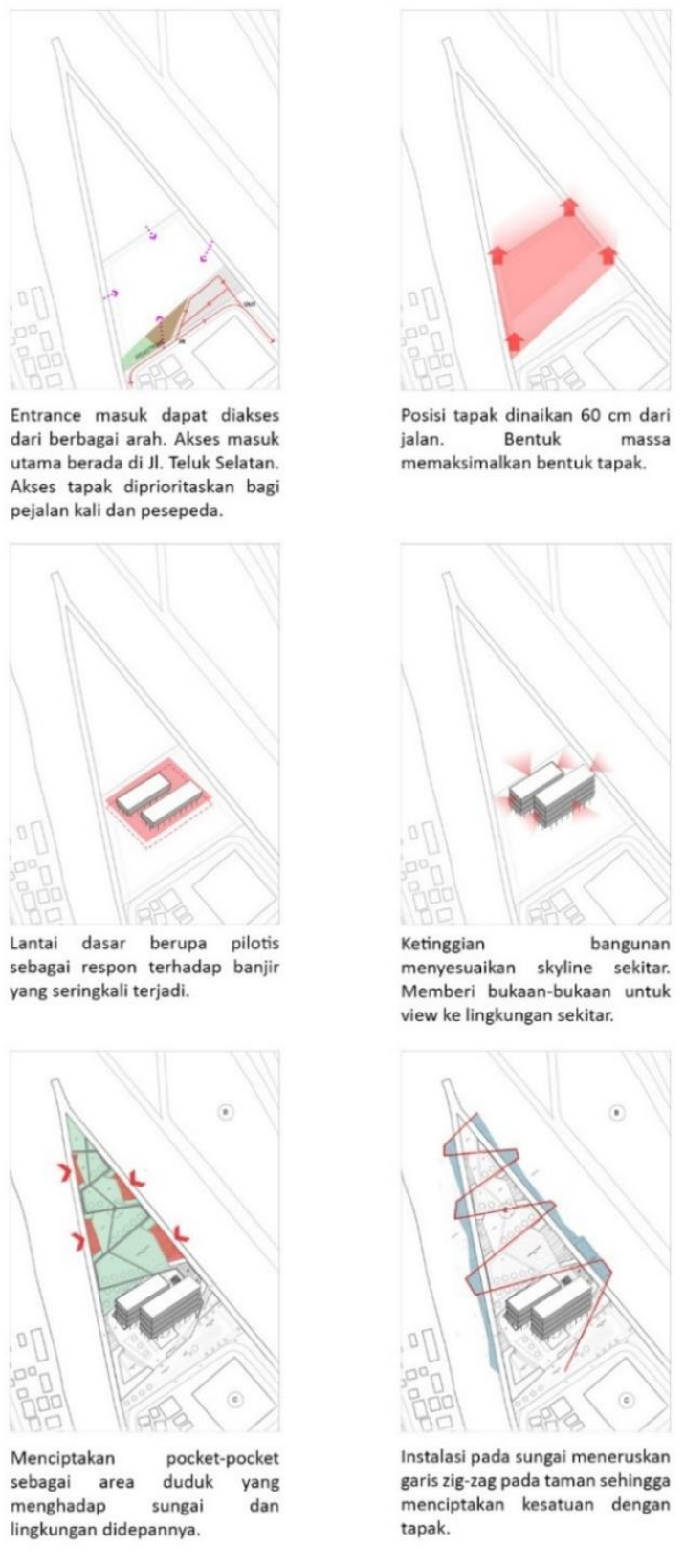
utama berada di II. Teluk Selatan. Akses tapak diprioritaskan ba pejalan kali dan pesepeda.

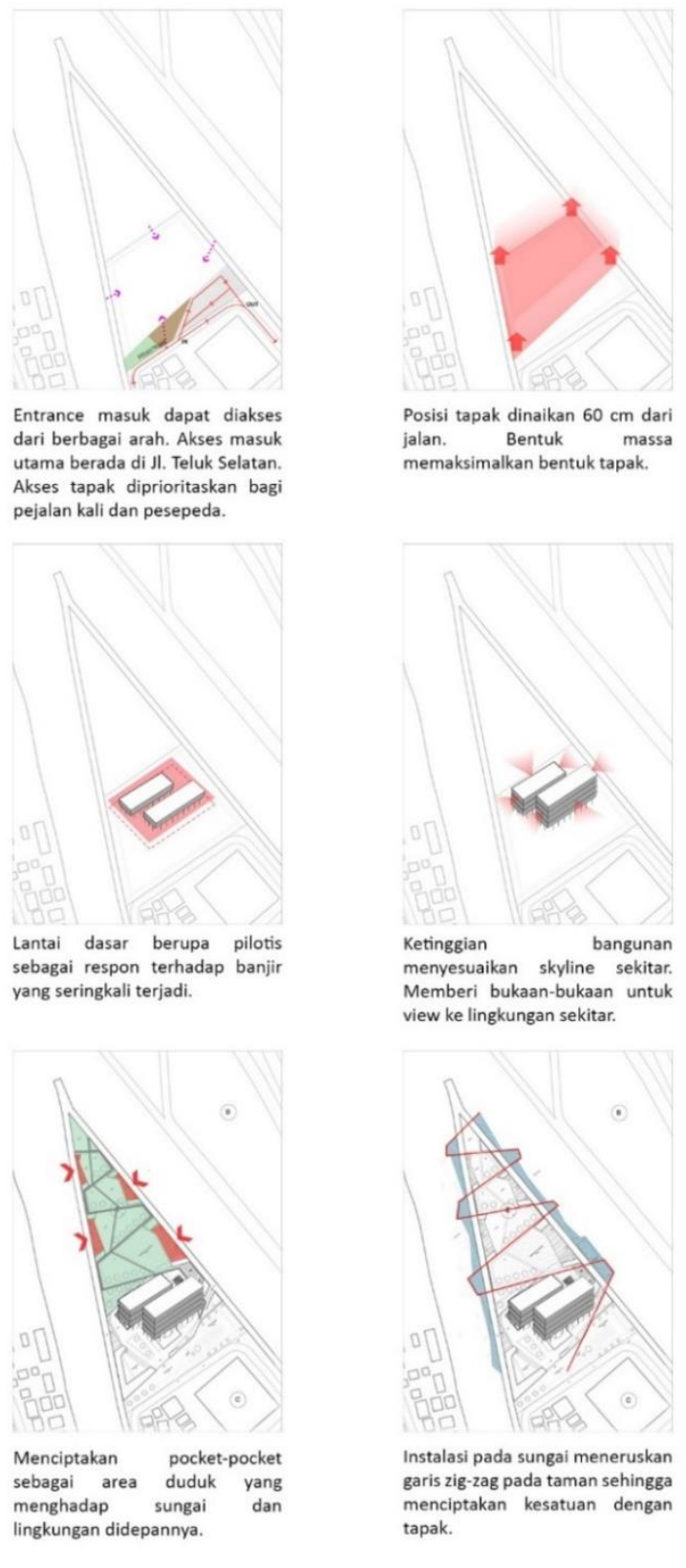
sebagai respon terhadap banjir yang seringkali terjadi.
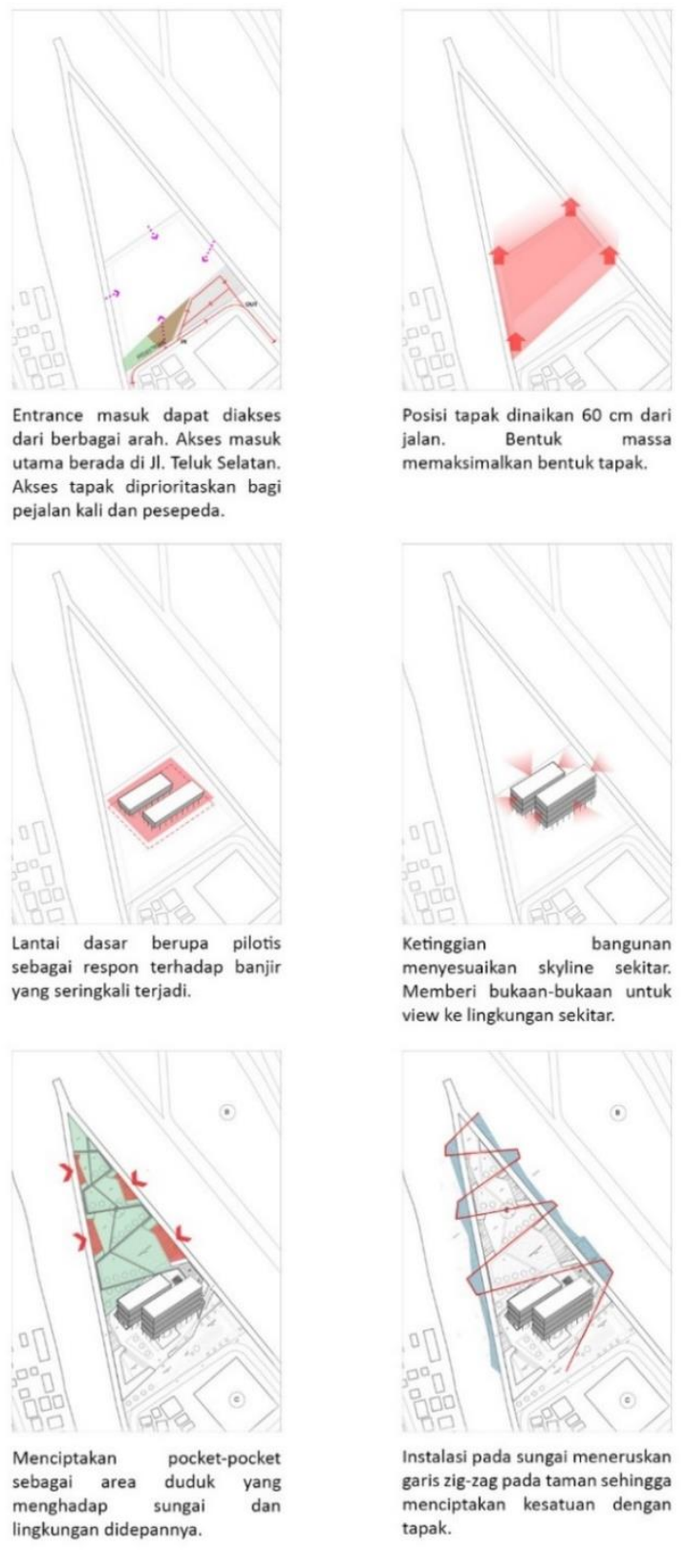

view ke lingkungan sekitar

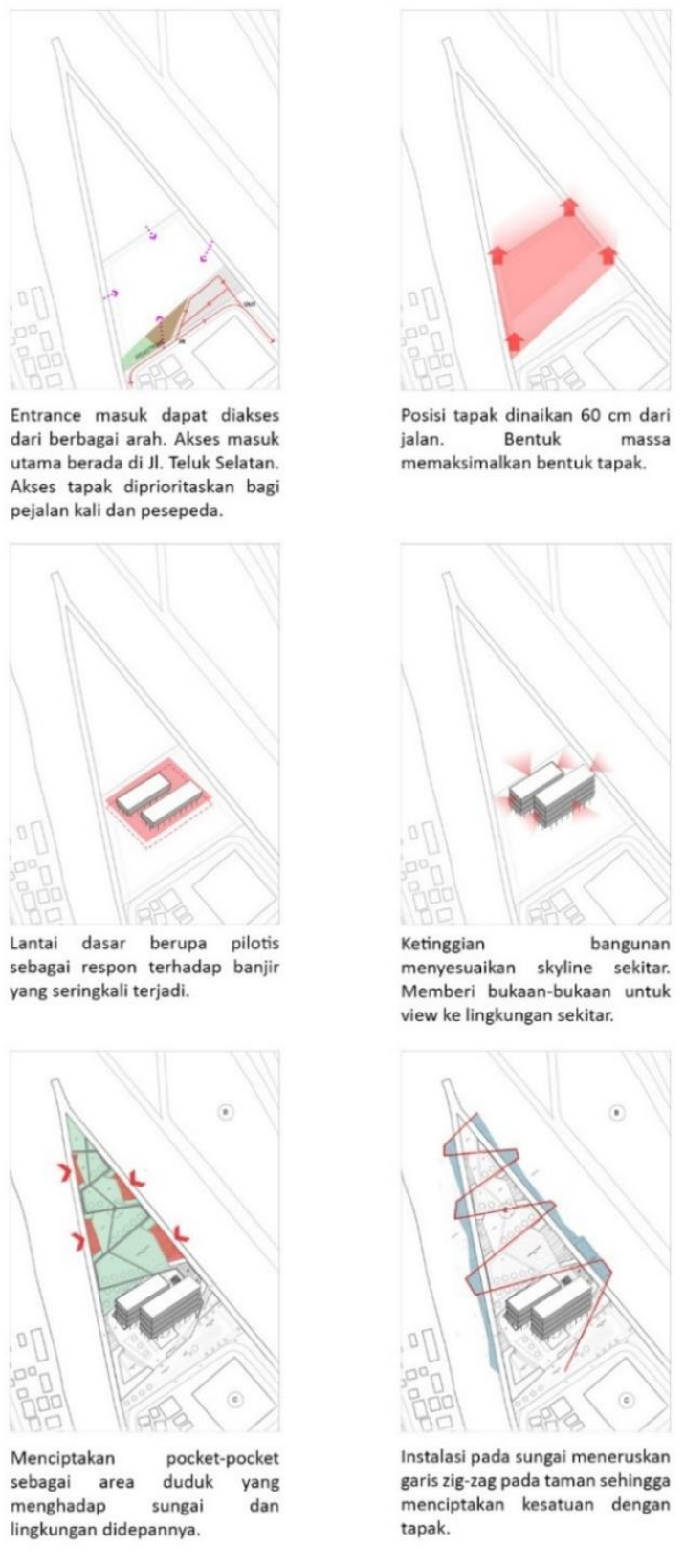

menciptakan kesatuan dengan tapak. jalan. Bentuk massa Memberi bukaan-bukaan untuk 
Instalasi pada sungai memiliki berbagai fungsi seperti canoe deck (yang menjadi dermaga dan menghubungkan dengan SMMA dan Mangrove Ecotourism melalui jalur sungai), fishing deck, dan swimming deck.

Area terbuka hijau menjadi area rekreasi warga seperti piknik, jogging, bermain, duduk-duduk dan berbincang-bincang. Area taman juga dihiasi patung pada beberapa titik. Area taman ditanami vegetasi riparian baik berupa pohon, perdu atau tanaman bunga. Pada community garden ditanamai tanaman sayur musiman. Hasil panen dapat dijual di retail atau digunakan untuk bahan makanan pada foodcourt atau café.

Program pada lantai dasar berupa kegiatan publik tidak berbayar. Program lantai 2-4 berupa kegiatan publik berbayar dan tak berbayar. Program lantai dasar terdiri atas kegiatan sosial, bermain, area hijau, dan area biru yang dipecah dan diacak peletakannya sehingga pesebaran kegiatan lebih merata. Bangunan terdiri atas 2 massa. Massa pertama berisi kegiatan kuliner, dan massa kedua berisi kegiatan pelatihan, seni, dan retail.

Pada area entrance tapak terdapat area parkir outdoor. Sirkulasi parkir kendaraan dari jalan utama kendaraan dapat drop off terlebih dahulu lalu menuju area parkir, atau langsung keluar ke jalan utama. Area taman terdapat jalan setapak bagi pejalan kaki dengan sirkulasi berbentuk zig-zag. Pada jalan inspeksi dapat dilalui oleh pejalan kaki dan pesepeda.
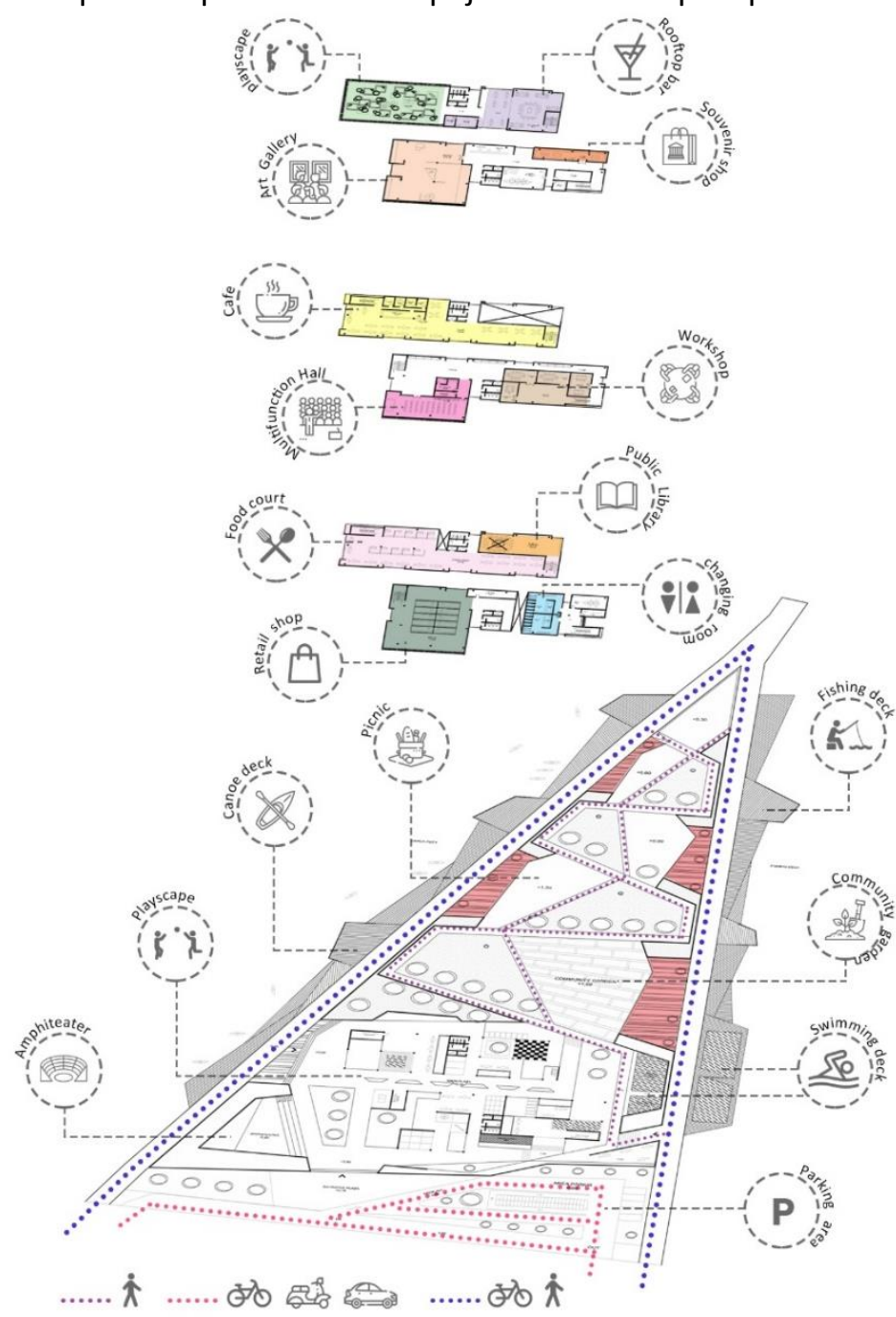

Gambar 7. Program Tapak

Sumber: Penulis, 2021 


\section{Karakter Beyond Ecology}

River Cultural Center memiliki 3 karakter beyond ecology yakni:

1. Context, posisi bangunan dinaikan dengan penggunaan pilotis pada lantai dasar sebagai antisipasi terhadap banjir.

2. Resilience, dengan mengembalikan fungsi ruang terbuka hijau sehingga menciptakan kembali habitat bagi sereangga dan hewan sungai lainnya. Selain itu juga melalui pemakaian ulang air bekas menjadi air bersih melalui filtrasi dengan hydrobotanic regeneration pond yang membentuk siklus tertutup.

3. Adapatation, program lantai dasar yang fleksibel. Ketika tidak banjir lantai dasar berupa sarana sosial, olahraga, dan bermain. Ketika banjir, area sungai akan meluas hingga ke tapak. Area canoe juga semakin lebar ke tapak. Program lantai atas masih dapat berjalan. Akses ke bangunan dengan canoe.

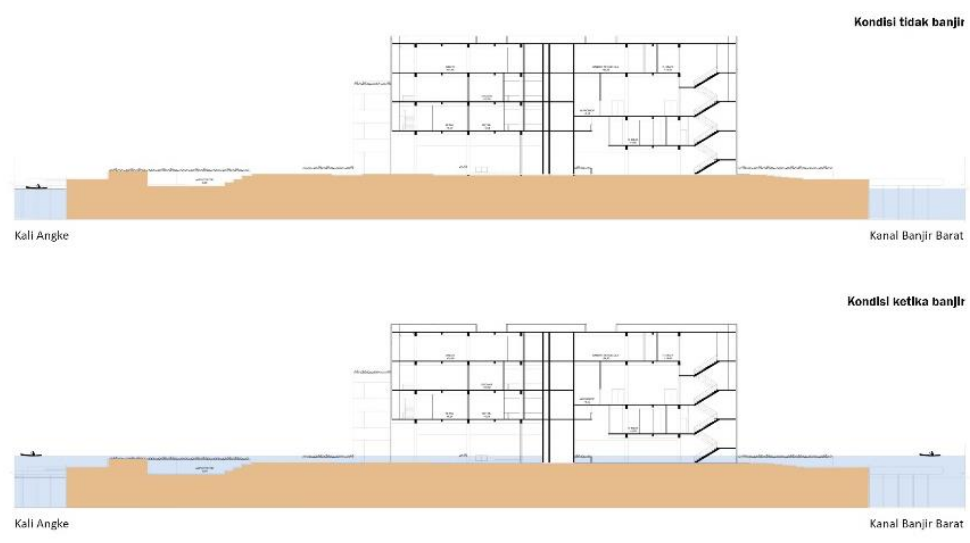

Gambar 8. Kondisi tidak banjir dan kondisi ketika banjir Sumber: Penulis, 2021

\section{Sistem Struktur}

Bangunan menggunakan system struktur kolom balok. Struktur bangunan terdiri atas kolom beton dengan diameter $40 \mathrm{~cm}$ dengan jarak antar kolom 7,2 m. balok induk $30 \times 60 \mathrm{~cm}$ dan balok anak $20 \times 40 \mathrm{~cm}$ dan core.

\section{Sistem Utilitas}

Sumber listrik berasal dari genset dan PLN yang kemudian disalurkan ke trafo, lalu ke panel induk dan didistribusikan ke panel cabang tiap lantai ke stop kontak dan lampu.

Sistem penghawaan dengan AC split VRV hanya digunakan pada ruang tertentu seperti galeri, kantor, dan ruang serba guna. Outdoor AC diletakan di dak di lantai atap. Selebihnya menggunaan bukaan-bukaan yang memungkinkan pertukaran aliran udara alami.

Sirkulasi vertikal yang digunakan berupa lift pada core dan tangga. Tiap bangunan memiliki 2 tangga yang terletak di masing-masing ujung bangunan.

Pada sistem Kebakaran, air dari GWT dipompa dan disalurkan ke sprinkle dan hydrant. Jika kehabisan persediaan air dapat menggunakan air sungai.

Sistem Air Bersih menggunakan air dari PDAM yang disalurkan ke GWT, lalu dipompa ke reservoir atas untuk kemudian disalurkan ke toilet dan wastafel secara gravitasi.

Pada sistem air kotoran (black water) dari toilet, akan disalurkan ke septictank dan sumur resapan kemudian disalurkan ke riol kota. Pada sistem air bekas (grey water) dari toilet, wastafel, dan kolam renang disalurkan terlebih dahulu ke ruang pompa. Kemudian akan dipompa melewati gravel filter bed dan hydrobotanic regeneration pond. Setelah melalui hydrobotanic regeneration pond akan disalurkan kembali ke ruang pompa untuk dipompa kembali ke toilet, wastafel dan kolam renang.

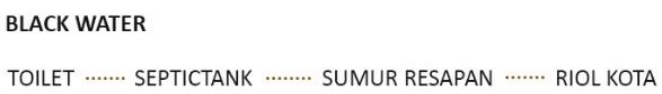




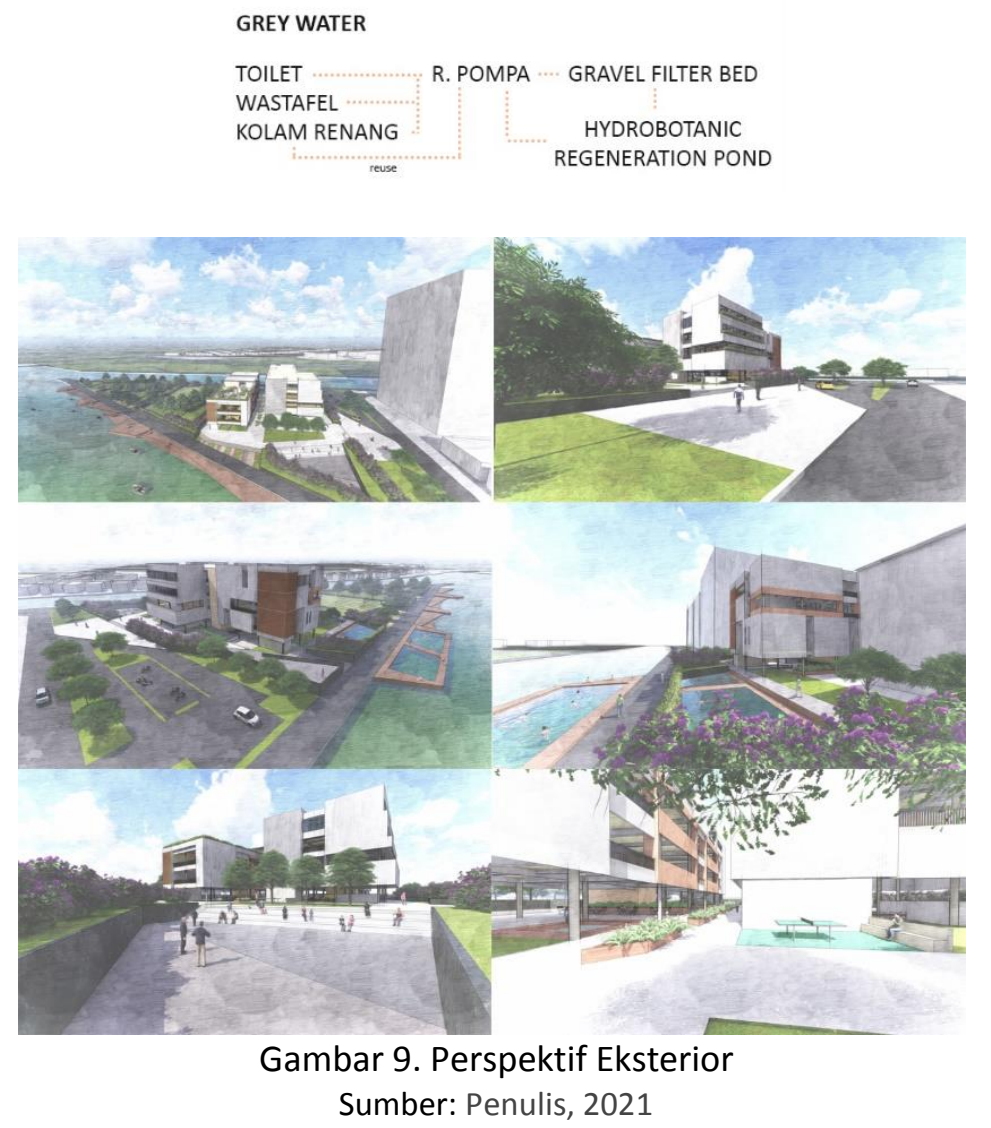

\section{KESIMPULAN DAN SARAN}

\section{Kesimpulan}

Seiring dengan perkembangan kota Jakarta yang semakin modern muncul juga pandangan masyarakat yang dapat memberikan implikasi yang bersifat destruktif terhadap sungai dan menghilangkan apresiasi masyarakat kota terhadap sungai. Hal ini dikarenakan masyarakat tidak memiliki sense of belonging terhadap alam kota yang juga diakibatkan karena keterbatasan akses. Keterbatasan akses ini menciptakan jarak antara manusia dan juga alam kotanya. Untuk menjaga dan melestarikan sungai, masyarakat harus mengenal dahulu sungainya dengan mendekatkan sungai dengan masyarakat. Maka perlu suatu area publik sebagai area berkumpul masyarakat dengan program-program yang dapat mendekatkan masyarakat dengan sungai. Metode pendekatan keseharian digunakan untuk menentukan program yang sesuai dengan kegiatan eksisting di daerah sekitar agar tercipta suatu peleburan. Program usulan terdiri atas 3 kelompok besar yaitu kuliner, olahraga dan kesenian. Kemudian peletakannya dibagi menjadi 3 zona sesuai interaksinya. Ruang publik menerapkan prinsipprinsip ekologi sehingga orientasi tidak hanya pada manusia tapi juga alam sekitar (sungai, hutan kota, dan lingkungan perumahan sekitar) dengan permasalah utama tapak yaitu banjir.

\section{Saran}

Pada proses perancangan ini, penulis menyadari kekurangan dalam gubah massa yang belum dapat memaksimalkan view terhadap sungai dan bentuk yang masih terkesan kurang berani. Oleh karena itu pendekatan desain yang berbeda diharapkan agar dapat memberi pandangan baru terkait bentuk massa yang memberi kesan lebih menyambut. Penulis menyadari dalam penulisan jurnal ini masih banyak kekurangan lainnya, maka dari itu penulis mengharapkan kritik dan saran yang membangun sebagai perbaikan terhadap perancangan ini. Terakhir, penulis berharap jurnal ini dapat memberi sedikit kontribusi wawasan dalam bidang arsitektur bagi pembaca. 


\section{Referensi}

Breen, A. dan Rigby, D. (1994). Waterfronts Cities Reclaim Their Edge. New York: Mcgraw-hills. Ismaniah, Cicik. (2018). Dinamika Hidrosfer.

Dewi P, I. (2017). Kajian Konsep Pengembangan Waterfront Berbasis Desain Ekologis di Cibinong Raya, Bogor: Institut Pertanian Bogor.

Prominski, M. dkk. (2012). River. Space. Design. Basel: Birkhouser

Republik Indonesia. (2011). Peraturan Pemerintah Republik Indonesia Nomor 38 Tahun 2013 Tentang Sungai. Jakarta: Kementerian Sekretariat Negara.

Sutanto, A. (2021, Februari). Dromos Oikos: Notes on The Fifth Ecology. Jakarta: Universitas Tarumanagara.

Sutanto, A. (2020). Peta Metode Desain. Jakarta: Universitas Tarumanagara.

Timur, U.P. (2013). Urban Waterfront Regeneration. Intech. Advance in Landscape Architecture, 169-205.

Yang, D. (2006). Waterfront: Spatial Composition and Cultural Use, London: University College London.

Zhang, L. (2002). An Evaluation of An Urban Riverfront Park. Washington: Washington State University. 